\title{
IMPACT OF DIGITAL SUPPORTED PROCESS WORKFLOW OPTIMIZATION FOR HIP JOINT ENDOPROSTHESIS IMPLANTATION ON HOSPITAL-SPECIFIC PROCESS AND QUALITY RATIOS
}

\author{
Benjamin Lahmann ${ }^{1}$, David Hampel ${ }^{1}$ \\ ${ }^{1}$ Department of Statistics and Operation Analysis, Faculty of Business and Economics, Mendel University in Brno, \\ Zemědělská 1, 61300 Brno, Czech Republic
}

Link to this article: https://doi.org/10.11118/actaun202068040755

Received: 11. 6. 2020, Accepted: 6. 8. 2020

To cite this article: LAHMANN BENJAMIN, HAMPEL DAVID. 2020. Impact of Digital Supported Process Workflow Optimization for Hip Joint Endoprosthesis Implantation on Hospital-specific Process and Quality Ratios. Acta Universitatis Agriculturae et Silviculturae Mendelianae Brunensis, 68(4): 755-763.

\begin{abstract}
Considering the continuous change within the German health care system, German hospitals are forced to realize efficiency gains and, at the same time, try to enhance their quality standards. Digital support systems in surgery rooms intend to improve operational efficiency and reduce failure quotas. A dataset with 383 hip joint endoprosthesis surgeries from a German hospital was analysed using statistical methods, among others logit model, odds ratio and ANCOVA. Results show that digitally supported surgery results in a shorter hospital stay time and reduces acute hemorrhagic anemia as a postoperative complication. Finally, it is possible to conclude that the Surgical Procedure Manager reduces surgical risks.
\end{abstract}

Keywords: digital support, endoprosthesis, hospital health care, process standardization, surgical procedure manager

\section{INTRODUCTION}

German hospitals are facing intense cost pressure and are increasingly confronted with competition. According to the diagnosis-related groups (DRG) principles, the introduction of the per-case reimbursement as a result of a German health care reform assigns hospitals health insurance payments by case type rather than by effort per case. For transparency reasons, extra efforts have to calculated according to a specific set of reimbursable treatment options and depending on reproducible case requirements (Hajen et al., 2011; Zapp et al., 2011). According to the Hospital Structure Act, surcharges and fee rebates are granted when quality and process standards, according to the Institute for Quality Assurance and Transparency in Health Care (IQTIG), are met (Richter-Kuhlmann et al., 2017). This principle forces hospitals to control expenses per patient and possibly standardize treatments in order to control case-specific costs. Non-profit and private profitable hospitals compete based on similar conditions. Like a private institution, the public institution has to adopt economic structures and processes to survive and remain competitive and keep their independence (Rausch, 2007; Schmid and Ulrich, 2013).

Standardized and high-quality principles of process management support hospitals in achieving their cost and profitability targets and additionally in meeting the documentation requirements of health insurances (Zapp et al., 2011; Kuy and Romero, 2017; Souders et al., 2017). Surgery 
processes offer particular standardization and optimization potentials: the establishment of quality and process standards reduces failure quotas and run through times and, in effect, operating room capacity utilization (Boos and Goldschmidt, 2000; Abollado et al., 2017; Carvajal et al., 2018). Such rationalization saves staff expenses per patient, frees capacity for new surgery jobs, and at the same time enhances patient care: Short anesthetic and surgery times reduce complication quotas and fatalities. Consecutive shorter hospital stays improve patients' convenience and satisfaction (Kuy and Romero, 2017; Souders et al., 2017). Quality improvements in surgery rooms, which ideally are achieved by standardizing operation workflows, result in a win-win situation for hospitals and patients. Assessment of standardized operation workflows addresses both efficiency and quality enhancements in surgical practice.

Efficiency is the capability to work in a quick and organized way. It distinguishes from effectiveness, which refers to the ability to produce the desired results, even if this is not efficient (Laitinen et al., 2018). The term efficiency is used synonymously to "ability to perform", and the efficiency construct is adequate to compare the implementation of different solutions concerning their economic effect, e.g., cost reduction, profitability and output amount (British Standards Institution, 2002; Smith, 2005; Chinubhai, 2011). The economic science of operations management concerns the optimization of efficiency in organizations by optimizing resource flows, service provision, and supply chain activities (Slack and Brandon-Jones, 2019). Operations management integrates the activities in the corporate value chain to efficiently transform input factors into economic outputs (Schroeder et al., 2016). Efficiency is not limited to the operational level but measured as the company's ability to fulfill market requirements profitably, e.g., operate competitively (Ross and Droge, 2004). Studies have long confirmed that in operations research, the optimization of process flow efficiency is inseparable from customer value creation (Heikkilä, 2002).

The DRG reimbursement system established in German hospitals based on the 2000 health reform has forced hospitals to improve the efficiency of treatment processes and operational standard systems and to calculate based on flatrate remuneration and treatment outcomes (Zapp and Schmidt-Rettig, 2015; Paeger, 2017). Since the 1990ies, increasingly public and non-profit hospitals have been privatized, which has increased the pressure to reduce costs and maximize profitability (Simon, 2017; Busse and Berger, 2018). Surgery efficiency contributes decisively to hospital efficiency, and operation room expenses account for about $40 \%$ to total operational costs (Behar et al., 2018). The optimization of operation room efficiency is a significant target in clinical efficiency management.
Typical efficiency measures in hospitals are process-related (e.g., assess process time, process quality, capacity) or financial (e.g., assess productivity, profitability, liquidity or investment), see Zapp, 2010, 2014; Paeger, 2017; Behar et al., 2018. In operation room efficiency enhancement, the reduction of run-through time is crucial. Standard measures are cutting-suture time, preparation time, and change time (Busse, 2010; Divatia and Ranganathan, 2015). The reduction of run-trough times save room capacities and staff resources and thus controls operation-specific costs (amounting from 10 to $120 €$ per minute in Germany), provided the saved capacities and resources are used efficiently otherwise (Busse, 2010; Macario, 2010). The efficiency and quality of operation flows are constituent for later-stage treatment efficiency. The reduction of surgery complications reduces post-operative stay times in hospitals (Lauterbach et al., 2013; Behar et al., 2018). In empirical medical efficiency management studies are efficiency gains due to the rationalization and standardization of surgical processes documented: Day surgery in Norwegian hospitals enhance technical efficiency, e.g., resource usage (Martinussen and Midttun, 2004). The switch from endoscopic surgeries outside of operation rooms to ambulant environments enhances profitability due to reduced capacity costs and patient stay times (Chatterjee et al., 2011). A change in Australian hospitals organization structure ensures long term cost efficiency (Braithwaite et al., 2006).

The facts, as just stated, imply that operational efficiency is inseparable from the fulfillment of quality standards. Quality describes the set of physical and immaterial characteristics of a product or service. This catalog of attributes is intended to fulfill the function or intention of the product or service from the perspective of its users or recipients, i.e., meet the requirements of the target market (Crozier, 2006; Mitra and Golder, 2006). Quality management concepts and frameworks are established in management practice. They comprise the Total Quality Management framework, ISO $9000 \mathrm{ff}$ standard, and the European Foundation for Quality Management model, for instance (Ribbeck, 2018). These approaches provide organizations with objectives, rules, and principles to implement processes and produce outputs that correspond to norms and satisfy customer's requirements and markets (Brabandt, 2017). These principles agree that quality management is a bottom-up process: i.e., has to be implemented from a tiny process flow upwards to realize a convincing high-quality product or service output (Mathar and Scheuring, 2011). The planning, monitoring, evaluation, and continuous improvement of process and production flows enables businesses to improve their quality standards continuously and in result efficiency and customer satisfaction (Günther, 2010; Robbins, 2011). 
Surgery efficiency and surgery quality are interdependent. Quality optimization is crucial from a humanitarian perspective: The avoidance of surgery complications enhances patient's health perspectives and survival quotas. The documentation of intra- and postoperative complications in surgery is required by law and internal hospital quality insurance (Zapp, 2010; Busse and Berger, 2018). Typical measures for postoperative complications in implantation surgery and specifically in hip replacement surgery are blood loss (acute hemorrhagic anemia), surgery complications (intraoperative) and (postoperative) complications with the implant (Nutt et al., 2013; Coomber et al., 2016; Erivan et al., 2018; Fawsitt et al., 2019). Empirical studies prove the impact of quality enhancement strategies in a surgery context to both patient health and economic efficiency. According to a patient-data-based simulation in the US federal state of New York, the patient's choice of certified high-quality hospitals increases their survival time and diminishes medical treatment costs (Wang et al., 2015). Feedback on surgery performance enhances their technical surgery performance (Hull et al., 2011). Diminishing the stress of Chinese health care staff by standardizing processes improves the quality of health care as perceived by patients as well as health outcomes (Ma et al., 2018). Only one study (Feige et al., 2017) on the quality effects of digital workflow support technologies such as Surgical Procedure Manager (SPM) has been identified. It explores the quality (section-suture time) and efficiency effects (process reliability, documentation compliance, and communication effectiveness of staff) for Functional Endoscopic Sinus Surgeries based on a comparison of mean values between a sample using SPM and another dispensing with SPM (Feige et al., 2017). Due to the limited sample size and a limited range of parameters, the insights gained in the study are not valid enough that its results could be directly transferred to other surgical procedures.

Standardization and quality control of perioperative processes based on digital technologies has been a concern of medical research and development for about two decades now (Neumuth et al., 2011). Based on surgical process models, i.e., descriptions of all steps necessary to implement certain surgical routines professionally, automated programs have been developed to guide surgeons by using a defined digital workflow through the operation process. Nowadays, several programs with different approaches for standardization are available on the market. Currently, there is only one market-ready software solution focusing on the workflow-based digitization of perioperative processes named Surgical Procedure Manager (Strauss et al., 2010, 2012). The effectiveness of these digital support routines to enhance the quality of medical care and the health outcome for patients, however, has hardly been analyzed based on empirical data.
This paper aims to assess the impact of SPM on quality and economic efficiency outcomes for hip joint endoprosthesis based on a representative dataset of patients in a German hospital.

\section{MATERIALS AND METHODS}

The study is based on a raw data set of 383 hip joint endoprosthesis implantations (OPS-Code: 5-820) realized at a German hospital in the period from September 4, 2015, to March 30, 2020. The surgical team switched from conventional non-software guided operation procedures to SPM guided processes by June 12, 2019. That means the dataset contains 324 pre-SPM implementation surgeries and 59 post-SPM implementation surgeries.

The endoprosthetic surgery team themselves developed the SPM based surgical pathway by standardizing their commonly applied methods into a digital program routine. Thus, the SPM system corresponds to the ideal previous standard of operation but ensures that a homogenous standard, following all requirements, is applied for every surgery by now. The result could be process improvement since deviations from the proven scheme are avoided. The routine contains processes to be followed except in case of extraordinary events, which are difficult to standardize due to their unpredictability. The data collected for all, pre- and post-SPM implementation, endoprosthetic surgeries correspond in content. Data and control parameters used for the subsequent evaluation are summarized in Tab. I. The codes mentioned in the table are assigned to prepare the dataset, and 12 datasets with partially missing information are deleted. The final data set contains 371 patients, of which 312 have been operated before SPM implementation and 59 with support of the SPM system. Based on these data, following hypotheses will be tested:

Efficiency increases due to SPM, specifically SPM reduces:

a) cutting-suture time,

b) post-processing time,

c) patient preparation time,

d) duration entering and exiting from operation room,

e) duration arrival and exit recovery room, and

f) hospital stay time of the endoprosthetic patients as compared to the non-SPM sample.

Quality increases due to SPM, specifically SPM reduces:

a) acute hemorrhagic anemia,

b) implant complications, and

c) surgery complications of endoprosthetic patients as compared to the non-SPM sample.

Propensity score matching (PSM) is employed to estimate the effect of a treatment by accounting for the covariates that affect the treatment's effectiveness in causal inference settings (Rosenbaum and Rubin, 
1983). PSM is necessary here since the outcome of an endoprosthetic measure does not depend on the application of SPM only but equally on the conditions of the patient, for instance. The target groups of SPM-treated (ns = 59) and non-SPM treated $(\mathrm{nn}=312)$ patients do not correspond in size. The PSM test compares the covariates among matched individuals (corresponding in the covariates) that were treated with SPM or without, respectively. It compares the distribution of results for the matched group to the entire data set. Ideally, the covariates of both datasets should correspond in distribution. The PSM test substitutes a randomized, doubleblind test in a situation where randomization and double-blind studies are impossible. Here, for instance, the SPM and non-SPM samples are already defined, and surgeries completed at the beginning of the study so that randomization and doubleblind implementation are not feasible (Neuberg, 2003). The PSM uses a logistic regression model. It distinguishes the dependent variables 1 for SPM treatment and 0 for non-SPM treatment and the assumed confounders (i.e., variable associated with treatment and outcome). These are gender, age, and coxarthrosis as the primary diagnosis (M16.1). The resulting propensity score and covariates have to be balanced across treatment and comparison groups (Garrido et al., 2014).
After a successful propensity score matching pretest, a t-test of means equality for independent samples is conducted to assess the difference between the SPM treatment group and the control group concerning the interval scaled efficiency target parameters. Equality of variances was verified by Levene test and normality was confirmed by testing skewness and kurtosis (Sheskin, 2011).

Considering the binary scaling of the quality target parameters and the fact that the data are based on a case-control study, the odds ratio (OR) for the complications D62, T81, T84 is calculated. In this study, the odds ratio calculates the chance for developing a D62, T81, T84 complication as a patient in the non-SPM group (control group) compared to the chance of not developing any of these complications by surgery with SPM (treatment group). An odds ratio value greater than one means that respective complication for patients in the SPM group appears more often than in the nonSPM group. The percentage value can be calculated based on 1-OR, or the reciprocal odds ratio can be calculated with $1 / \mathrm{OR}$. If the confidence interval for the odds ratio includes one, the calculated odds ratio is considered for not being statistically significant. If it does not include one a statistically significant result is assumed (Altman, 1999; Persoskie and Ferrer, 2017; Agresti, 2019).

I: Evaluated data and control parameters

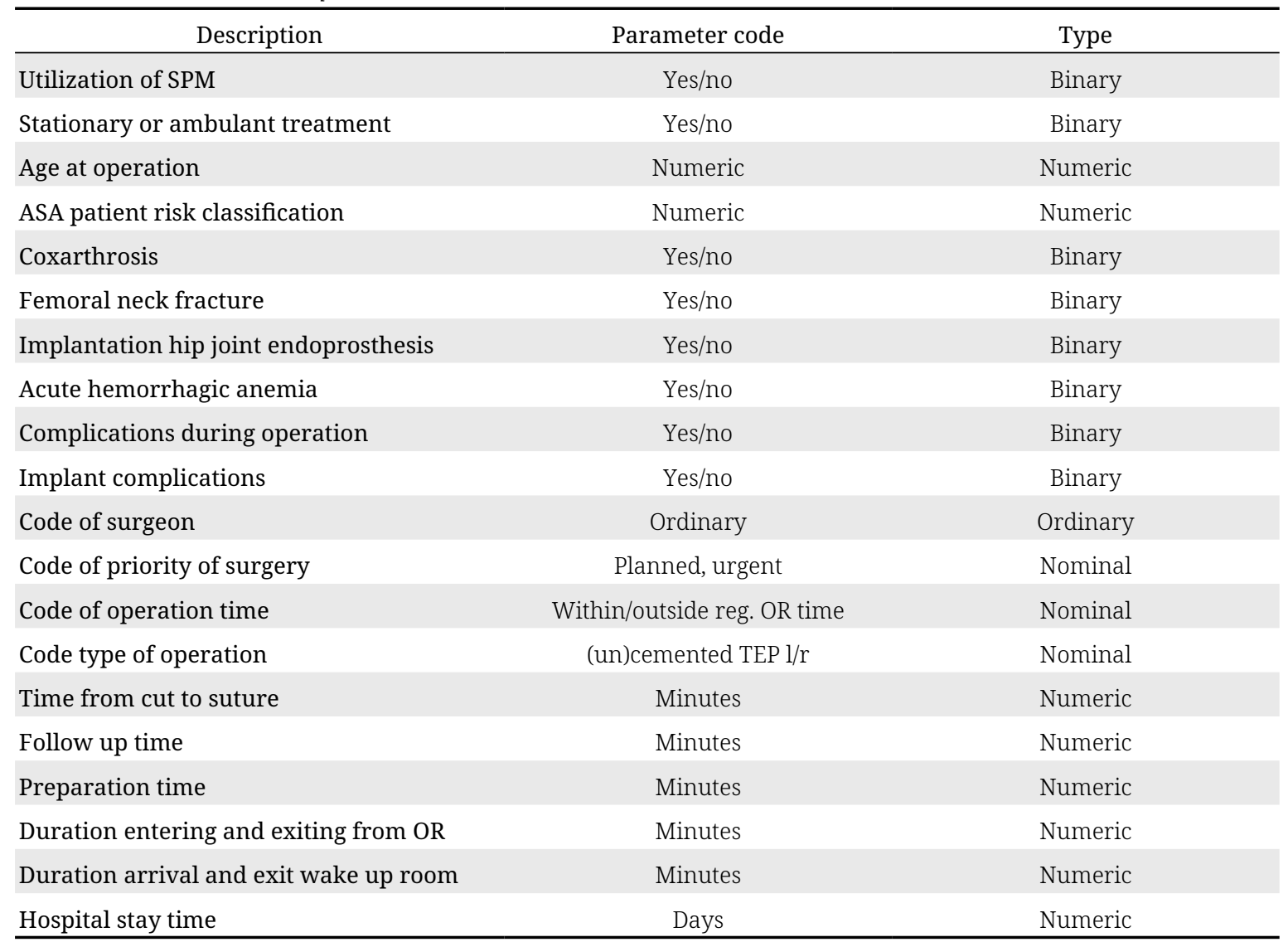


To further detail the results concerning the impact of control parameters, an ANCOVA analysis is conducted which controls the moderating impacts of surgeon, priority, operation time, and intervention type on the effect of SPM/non-SPM on the quality and efficiency target parameters. Skewness and kurtosis test confirmed normality of the data and equality of variances was verified by Levene test (Sheskin, 2011). Finally, a binary logistic regression, called logit model, is used to check whether there is a relationship between a dependent binary variable and one or more independent variables. In this case, the binary-scaled complications D62, T81, and T84 are the dependent variable, and the independent variables are surgeon, priority, surgery time, and intervention type. All calculations were done in SPSS software; significance level of 0.05 was used.

\section{RESULTS}

Descriptive analysis of the covariates results that $69.5 \%$ of the patients are female. The average age is 71.6 years, with a minimum of 45 and a maximum of 97. Almost all patients are treated stationary (99.4\%). Most operations are planed (84.1\%), the other $15.9 \%$ are urgent. $89.5 \%$ of the operations take place within regular operation time. During the observation period, these evaluated operations were performed by seven different surgeons, whereby four of them have operated in both the control and treatment groups. The majority of the operations were performed by a single surgeon, who performed 177 of the 371 operations. Two others performed 61 and 53 of the procedures, and another surgeon performed 19 operations. Thus, these four surgeons are included as surgeons in both groups, and the percentage distribution of operated patients is nearly balanced between these surgeons in the control and treatment groups. The majority of operations are without surgery complications (96\%). Furthermore, implant complications are rare (4.31\%). However, acute hemorrhagic anemia (D62) is common practice with $41.8 \%$ of patients, since the implantation of the endoprosthesis is a relatively invasive procedure.

The results of the propensity score matching show that the part groups of patients treated with the support of SPM and without the SPM system do not differ significantly on gender and age and primary diagnosis. The t-test examines whether the SPM and non-SPM subsamples differ concerning the efficiency parameters, thereby testing the hypotheses. Tab. II details the t-test results for the efficiency parameters when differentiating SPM supported and non-SPM supported interventions. SPM supported interventions significantly differs from non-SPM ones for hospital stay time and duration of arrival and exit from the recovery room, while the other tests on differences for operation times and part times showing no significant differences between the groups. Hospital stay times are significantly shorter for SPM treated patients (9 days as compared to 11.07 days without SPM). The duration of arrival and exit from the recovery room is also significantly shorter for SPM treated patients (76.74 minutes as compared to 88.97 minutes without SPM).

The odds ratio examines whether the SPM and non-SPM subsamples differ in quality parameters, thereby testing the hypotheses. The odds ratio for D62 is 0.301 , which implies that the chance for the occurrence of D62 is $69.92 \%$ lower within the SPM group or 3.3 times higher within the no-SPM group compared to the SPM group. The result is significant. The odds ratio for T81 is 0.811 , which implies that the chance for the occurrence of T81 is $18.90 \%$ lower within the SPM group or 1.2 times higher within the no-SPM group compared to the SPM group. The result is significant. Finally, the odds ratio for T84 is 0.591 , which implies that the chance for the occurrence of T81 is 1.7 times higher within the no-SPM group compared to the SPM group, but this result is not statistically significant.

To analyze the impact of other factors that were not considered in the t-test of means equality, an ANCOVA analysis is performed for the efficiency parameters. This analysis considers the following additional moderating input factors: surgeon, operation priority, the timing of the operation, type of operation. Time efficiency-related results are indicated in Tab. III, which illustrates that cuttingsuture time, post-processing time, and duration from entering and exiting from operation room depend on the operation's priority only. Preparation time depends on the intervention type and operation time. Duration of arrival and exit from

II: Result t-test of means equality of efficiency parameters differentiating by SPM and non-SPM

\begin{tabular}{lccc}
\hline \multicolumn{1}{c}{ Efficiency targets } & mean no SPM & mean SPM & p-value \\
\hline Cutting-suture time [min] & 69.11 & 66.71 & 0.455 \\
Post-processing time [min] & 7.00 & 7.72 & 0.279 \\
Patient preparation time [min] & 43.85 & 44.70 & 0.606 \\
Total turnover time [min] & 123.84 & 123.07 & 0.838 \\
Recovery room time [min] & 88.97 & 76.74 & 0.009 \\
Hospital stay time [days] & 11.07 & 9.00 & 0.001 \\
\hline
\end{tabular}


III: ANCOVA-test of factors impacting time efficiency of operation, p-values

\begin{tabular}{lcccccc}
\hline & $\begin{array}{c}\text { Cutting } \\
\text { suture time }\end{array}$ & $\begin{array}{c}\text { Post processing } \\
\text { time }\end{array}$ & $\begin{array}{c}\text { Patient } \\
\text { preparation time }\end{array}$ & $\begin{array}{c}\text { Total turnover } \\
\text { time }\end{array}$ & $\begin{array}{c}\text { Recovery } \\
\text { room time }\end{array}$ & \multicolumn{2}{c}{$\begin{array}{c}\text { Hospital stay } \\
\text { time }\end{array}$} \\
\hline Surgeon code & 0.383 & 0.849 & 0.801 & 0.768 & 0.921 & 0.016 \\
Priority code & 0.010 & 0.041 & 0.842 & 0.001 & 0.001 & 0.087 \\
Operation time & 0.908 & 0.574 & 0.001 & 0.836 & $<0.001$ & 0.963 \\
Intervention type & 0.481 & 0.211 & $<0.001$ & 0.498 & $<0.001$ & 0.138 \\
SPM & 0.555 & 0.239 & 0.296 & 0.818 & 0.938 & 0.015 \\
\hline
\end{tabular}

IV: Binary logistic regression for quality-related parameters, $p$-values

\begin{tabular}{lcc}
\hline & Acute hemorrhagic anemia & Complication during operation \\
\hline Surgeon code & 0.322 & 0.008 \\
Priority code & 0.013 & 0.908 \\
Operation time & 0.823 & 0.074 \\
Intervention type & 0.22 & 0.057 \\
SPM & 0.001 & 0.997 \\
\hline
\end{tabular}

the recovery room depends on priority, intervention type, and operation time. The length of hospital stay depends largely and significantly on the evaluated factors surgeon and SPM application.

For the quality parameters D62 acute hemorrhagic anemia and T81 complications during surgery, the odds ratio has shown a significant impact of the SPM. However, the odds ratio does not consider the impact of other factors on the results. Therefore, a binary logistic regression is performed for D62 and T81. Tab. IV summarizes these results: D62 depends on the SPM application and on the priority of surgery; T81 depends only on the surgeon and not on the SPM. All insignificant variables were removed and all significant variables remained significant in the final model.

\section{CONCLUSION}

Obtained results show that the application of a digital workflow system for hip joint endoprosthesis implantations significantly reduces patient's hospital stay time but does not influence operation times itself. The SPM further enhances hip joint endoprosthesis implantation quality outcomes. Notably, the SPM application significantly reduces acute hemorrhagic anemia and therefore reduces surgeon related risk factors.

The positive impact of process efficiency optimization on economic performance, care quality, and health outcomes have repeatedly been confirmed (Hull et al., 2011; Wang et al., 2015; Feige et al., 2017; Ma et al., 2018). However, the impact of digital surgery support on efficiency and health care quality has hardly been examined yet. It is possible to declare that this paper closes this research gap: According to this study, process standardization in operation rooms in the form of digital operation support systems enhances the quality and efficiency of hip endoprosthetic surgeries.

However, some limitations of this analysis have to be observed. The results only concern the hip joint endoprosthesis and cannot be transferred indiscriminately to other types of surgical procedures. The sample of 59 SPM-supported operations collected in a single hospital in 2019/2020 is rather small and thus possibly not representative of other hospitals due to unknown bias. Mainly failure quotas concern only a few cases in both the control- and treatment groups, and the observed effects could be subject to significant random influences. Additionally, the data collection already started a few weeks after the implementation and kick-off-phase. Maybe the learning curve was not finished. Further quality and time efficiency gains could be realized when surgeons gather experience with the system. Research on the application of digital support systems in surgical practice by collecting data from other hospitals and other disciplines is desirable to improve the scientific understanding in this promising interdisciplinary field. 


\section{Compliance With Ethical and Data Protection Standards}

All analyses performed in this study with datasets from the treatment of patients were conducted in accordance with the ethical and data protection standards of the St.Marien hospital Friesoythe, the hospital that provided the dataset.

As this is a study in which retrospectively already documented data are analyzed and only published in an aggregated anonymous form, separate declarations of consent by individual patients are not necessary. No such informed consent statement was obtained for surgeon participation either, as these processed data are also anonymous data.

\section{REFERENCES}

ABOLLADO, J. R., SHEHAB, E. and BAMFORTH, P. 2017. Challenges and Benefits of Digital Workflow Implementation in Aerospace Manufacturing Engineering. Procedia CIRP, 60: 80-85.

AGRESTI, A. 2019. An introduction to categorical data analysis. $3^{\text {rd }}$ Edition. Wiley series in probability and statistics. Hoboken, NJ: John Wiley \& Sons.

ALTMAN, D. G. 1999. Practical statistics for medical research. Boca Raton, Fla: Chapman \& Hall/CRC.

BEHAR, B. I., GUTH, C. and SALFELD, R. 2018. Modern hospital management: concepts and solutions [in German: Modernes Krankenhausmanagement: Konzepte und Lösungen]. $4^{\text {th }}$ Edition. Berlin: Springer Gabler.

BRITISH STANDARDS INSTITUTION. 2002. Effective records management - Part 3: Performance management for BS. ISO 15489-1. BIP 0025-3:2003. BSI Business information: Jones, P. A.

BOOS, M. and GOLDSCHMIDT, N. 2000. Knowledge value!? economic perspectives of the knowledge society: $3^{\text {rd }}$ Freiburg Economic Symposium [in German: WissensWert!? ökonomische Perspektiven der Wissensgesellschaft: 3. Freiburger Wirtschaftssymposium]. $1^{\text {st }}$ Edition. Baden-Baden: Nomos.

BRABANDT, N. 2017. The solution to the leadership problem: Development of an effective and sustainable leadership model based on the experiences of management and leadership thinkers [in German: Die Lösung der Leadership-Problematik: Entwicklung eines wirksamen und nachhaltigen Führungsmodells auf Grundlage der Erfahrungen der Management- und Leadership-Vordenker]. $1^{\text {st }}$ Edition. Books on Demand.

BRAITHWAite, J., WESTBROOK, M. T., HINDLE, D., IEDEMA, R. A. and BLACK, D. A. 2006. Does restructuring hospitals result in greater efficiency - an empirical test using diachronic data. Health Services Management Research, 19(1): 1-12.

BUSSE, T. 2010. Operation room management: Basics [in German: OP-Management: Grundlagen]. $4^{\text {th }}$ Edition. Heidelberg: Medhochzwei-Verl.

BUSSE, R. and BERGER, E. 2018. From planning inventory protection to demand-oriented hospital services [in German: Vom planerischen Bestandschutz zum bedarfsorientierten Krankenhausangebot]. In: KLAUBER, J., GERAEDTS, M., FRIEDRICH, J. and WASEM, J. (Eds.). Hospital report 2018. Focus: Need and needs-based justice [in German: Krankenhaus-Report 2018. Schwerpunkt: Bedarf und Bedarfsgerechtigkeit]. Stuttgart: Schattauer.

CARVAJAL, G., MAUCEC, M. and CULLICK, S. 2018. Chapter Five - Workflow Automation and Intelligent Control. In: CARVAJAL, G., MAUCEC, M. and CULLICK, S. (Eds.) Intelligent Digital Oil and Gas Fields. pp. 149-195. Boston: Gulf Professional Publishing.

CHATTERJEE, A., MCCARTHY, J. E., MONTAGNE, S. A., LEONG, K. and KERRIGAN, C. L. 2011. A Cost, Profit, and Efficiency Analysis of Performing Carpal Tunnel Surgery in the Operating Room Versus the Clinic Setting in the United States: Annals of Plastic Surgery, 66(3): 245-248.

CHINUBHAI, A. 2011. Efficiency in Software Development Projects: . International Journal of Software Engineering and its Applications, 5(4): 171-179.

COOMBER, R., PORTEOUS, M., HUBBLE, M. J. W. and PARKER, M. J. 2016. Total hip replacement for hip fracture: Surgical techniques and concepts. Injury, 47(10): 2060-2064.

CROZIER, F. 2006. Terminology of quality assurance: towards shared European values? Helsinki: European Association for Quatity Assurance in Higher Education.

DIVATIA, J. and RANGANATHAN, P. 2015. Can we improve operating room efficiency? Journal of Postgraduate Medicine, 61(1): 1-2.

ERIVAN, R., LECOINTE, T., VILlATTE, G., MUlliEZ, A., DESCAMPS, S. and BOISGARD, S. 2018. Complications with cement spacers in 2-stage treatment of periprosthetic joint infection on total hip replacement. Orthopaedics \& Traumatology: Surgery \& Research, 104(3): 333-339.

FAWSITT, C. G., THOM, H. H. Z., HUNT, L. P., NEMES, S., BLOM, A. W., WELTON, N. J., HOLLINGWORTH, W., LÓPEZ-LÓPEZ, J. A., BESWICK, A. D., BURSTON, A., ROLFSON, O., GARELLICK, G. and MARQUES, E. M. R. 2019. Choice of Prosthetic Implant Combinations in Total Hip Replacement: Cost-Effectiveness Analysis Using UK and Swedish Hip Joint Registries Data. Value in Health, 22(3): 303-312. 
FEIGE, K., GOLLNICK, I., SCHMITZ, P. and STRAUSS, G. 2017. The application of surgical procedure manager (SPM): first experience with FESS. European Archives of Oto-Rhino-Laryngology, 274(9): 3407-3416.

GARRIDO, M. M., KELLEY, A. S., PARIS, J., ROZA, K., MEIER, D. E., MORRISON, R. S. and ALDRIDGE, M. D. (2014). Methods for Constructing and Assessing Propensity Scores. Health Services Research, 49(5): 1701-1720.

GÜNTHER, S. 2010. Design for Six Sigma: Design and operationalization of alternative problemsolving cycles based on evolutionary algorithms [in German: Design for Six Sigma: Konzeption und Operationalisierung von alternativen Problemlösungszyklen auf Basis evolutionärer Algorithmen]. $1^{\text {st }}$ Edition. Wiesbaden: Gabler.

HAJEN, L., PAETOW, H. and SCHUMACHER, H. 2011. Health economics: structures - methods - practical examples [in German: Gesundheitsökonomie: Strukturen - Methoden - Praxisbeispiele]. $6^{\text {th }}$ Edition. Stuttgart: Kohlhammer.

HEIKKILÄ, J. 2002. From supply to demand chain management: efficiency and customer satisfaction. Journal of Operations Management, 20(6): 747-767.

HULL, L., ARORA, S., KASSAB, E., KNEEBONE, R. and SEVDALIS, N. 2011. Assessment of stress and teamwork in the operating room: an exploratory study. The American Journal of Surgery, 201(1): 24-30.

KUY, S. and ROMERO, R. A. L. 2017. Improving staff perception of a safety climate with crew resource management training. Journal of Surgical Research, 213: 177-183.

LAITINEN, I., KINDER, T. and STENVALL, J. 2018. International Journal of Knowledge-Based Development. Local public service productivity and performance measurement, 9(1): 49-75.

LAUTERBACH, K., STOCK, S. and BRUNNER, H. 2013. Health economics: textbook for physicians and other health professionals [in German: Gesundheitsökonomie: Lehrbuch für Mediziner und andere Gesundheitsberufe]. $3^{\text {rd }}$ Edition. Bern: Verlag Hans Huber.

MA, T., YANG, T., GUO, Y., WANG, Y. and DENG, J. 2018. Do Challenge Stress and Hindrance Stress Affect Quality of Health Care? Empirical Evidence from China. International Journal of Environmental Research and Public Health, 15(8): 1628.

MACARIO, A. 2010. What does one minute of operating room time cost? Journal of Clinical Anesthesia, 22(4): 233-236.

MARTINUSSEN, P. E. and MIDTTUN, L. 2004. Day surgery and hospital efficiency: empirical analysis of Norwegian hospitals, 1999-2001. Health Policy, 68(2): 183-196.

MATHAR, H.-J. and SCHEURING, J. 2011. Logistics for technical business people and HWD basics with examples, repetition questions and answers and exercises [in German: Logistik für technische Kaufleute und HWD Grundlagen mit Beispielen, Repetitionsfragen und Antworten sowie Übungen]. Zürich: Compendio Bildungsmedien.

MITRA, D. and GOLDER, P. N. 2006. How Does Objective Quality Affect Perceived Quality? Short-Term Effects, Long-Term Effects, and Asymmetries. Marketing Science, 25(3): 230-247.

NEUBERG, L. G. 2003. CAUSALITY: MODELS, REASONING, and INFERENCE, by Judea Pearl, Cambridge University Press, 2000. Econometric Theory, 19(4): 675-685.

NEUMUTH, T., JANNIN, P., SCHLOMBERG, J., MEIXENSBERGER, J., WIEDEMANN, P. and BURGERT, O. 2011. Analysis of surgical intervention populations using generic surgical process models. International Journal of Computer Assisted Radiology and Surgery, 6(1): 59-71.

NUTT, J. L., PAPANIKOLAOU, K. and KELLETT, C. F. 2013. Complications of total hip arthroplasty. Orthopaedics and Trauma, 27(5): 272-276.

PAEGER, A. 2017. Hospital and DRG system - an introduction to incentive systems [in German: Krankenhaus und DRG-Systematik - eine Einführung in die Anreizsysteme]. In: DEBATIN, J. F., EKKERNKAMP, A., SCHULTE, B. and TECKLENBURG, A. (Eds.). Hospital management: strategies, concepts, methods [in German: Krankenhausmanagement: Strategien, Konzepte, Methoden]. $3^{\text {rd }}$ Edition. Berlin: Medizinisch Wissenschaftliche Verlagsgesellschaft.

PERSOSKIE, A. and FERRER, R. A. 2017. A Most Odd Ratio: American Journal of Preventive Medicine, 52(2): 224-228.

RAUSCH, K. 2007. Shaping the organization: Reconciling Structure with Culture, Volume for the $13^{\text {th }}$ Conference of the Society for Applied Business Psychology e. V. on 2 and 3 February 2007 at the FH Osnabrück [in German: Organisation gestalten: Struktur mit Kultur versöhnen; Band zur 13. Tagung der Gesellschaft für angewandte Wirtschaftspsychologie e. V. am 2. und 3. Februar 2007 in der FH Osnabrück]. Lengerich, Westf: Pabst Science Publ.

RICHTER-KUHLMANN, E., MAYBAUM, T. and BEERHEIM, R. 2017. Hospital: A question of quality [in German: Krankenhaus: Eine Frage der Qualität]. Aerzteblatt.de [Online]. Available at: https://www. aerzteblatt.de/archiv/192973/Krankenhaus-Eine-Frage-der-Qualitaet [Accessed: 2019, January 15]. 
ROBBINS, S. P. 2011. Management: the essentials. Frenchs Forest, N.S.W.: Pearson Australia.

ROSENBAUM, P. R. and RUBIN, D. B. 1983. The Central Role of the Propensity Score in Observational Studies for Causal Effects. Biometrika, 70(1): 41-55.

ROSS, A. D. and DROGE, C. 2004. An analysis of operations efficiency in large-scale distribution systems. Journal of Operations Management, 21(6): 673-688.

SCHMID, A. and ULRICH, V. 2013. Consolidation and concentration in the German hospital market: The two sides of the coin. Health Policy, 109(3): 301-310.

SCHROEDER, R. G., GOLDSTEIN, S. M. and RUNGTUSANATHAM, M. J. 2016. Operations management in the supply chain: decisions and cases. $7^{\text {th }}$ Edition. Dubuque: McGraw-Hill Education.

SHESKIN, D. 2011. Handbook of parametric and nonparametric statistical procedures. $5^{\text {th }}$ Edition. Boca Raton: CRC Press.

SIMON, M. 2017. The health care system in Germany: an introduction to its structure and functioning [in German: Das Gesundheitssystem in Deutschland: eine Einführung in Struktur und Funktionsweise]. $6^{\text {th }}$ Edition. Bern: Hogrefe.

SLACK, N. and BRANDON-JONES, A. 2019. Operations management. 9 th $^{\text {th }}$ Edition. Harlow, England; New York, US: Pearson.

SMITH, M. 2005. Performance measurement \& management: a strategic approach to management accounting. London, England; Thousand Oaks, Calif: SAGE.

SOUDERS, C. P., CATCHPOLE, K. R., WOOD, L. N., SOLNIK, J. M., AVENIDO, R. M., STRAUSS, P. L., EILBER, K. S. and ANGER, J. T. 2017. Reducing Operating Room Turnover Time for Robotic Surgery Using a Motor Racing Pit Stop Model. World Journal of Surgery, 41(8): 1943-1949.

STRAUSS, G., ARIES, F., ABRI, O., DIETZ, A., MEIXENSBERGER, J. and LÜTH, T. 2010. Konzeption, Realisierung und Analyse einer neuartigen OP-Konzeption für die HNO-Chirurgie. HNO, 58(11): 1074-1084.

STRAUSS, G., GOLLNICK, I., NEUMUTH, T., MEIXENSBERGER, J. and LUETH, T. 2012. The "Surgical Deck”: A new surgical generation for ENT surgery [in German: Das “Surgical Deck”: Eine neue OPGeneration für die HNO-Chirurgie]. Laryngo-Rhino-Otologie, 92(2): 102-112.

TRIPEPI, G., JAGER, K. J., DEKKER, F. W., WANNER, C. and ZOCCALI, C. 2007. Measures of effect: Relative risks, odds ratios, risk difference, and 'number needed to treat'. Kidney International, 72(7): 789-791.

WANG, G., LI, J., HOPP, W. J., FAZZALARI, F. L. and BOLLING, S. 2015. Hospital Quality and Patient Choice: An Empirical Analysis of Mitral Valve Surgery. Ross School of Business Paper No. 1386. University of Michigan.

ZAPP, W. 2010. Key figures in hospitals [in German: Kennzahlen im Krankenhaus]. $1^{\text {st }}$ Edition. Lohmar: Eul. (Reihe: Controlling and Management in Gesundheitseinrichtungen; 2).

ZAPP, W. 2014. Strategic development in hospitals: key figures - portfolio - geocoding - occupancy management [in German: Strategische Entwicklung im Krankenhaus: Kennzahlen - Portfolio Geokodierung - Belegungsmanagement]. $1^{\text {st }}$ Edition. Stuttgart: Verlag W. Kohlhammer.

ZAPP, W., GRUNDMANN, J., TERBECK, J., HEIER, K. and NIELSEN, S. 2011. Hospital productivity [in German: Produktivität im Krankenhaus]. KU Gesundheitsmanagement, 2011: 41-44.

ZAPP, W. and SCHMIDT-RETTIG, B. 2015. Hospital management: organizational change and leadership [in German: Krankenhausmanagement: organisatorischer Wandel und Leadership]. $1^{\text {st }}$ Edition. Stuttgart: Kohlhammer.

Contact information

Benjamin Lahmann: xlahmann@mendelu.cz

David Hampel: david.hampel.uso@mendelu.cz 